\title{
TATA CAHAYA HIGH CONTRAST SEBAGAI PENDUKUNG UNSUR DRAMATIS PADA FILM HOROR "DERANA DARA"
}

\author{
Bakti Taufikurrrahman \\ Alexandri Luthfi Rahman \\ Latief Rakhman Hakim
}

\begin{abstract}
ABSTRAK
Terjadinya tindak kekerasan dan pelecehan pada anak antaralain, kurangnya pengetahuan bagaimana menjadi orang tua, kemauan yang tak realitas kepada kecakapan dan perilaku anak, isolasi sosial, pemasalahan obat-obatan terlarang dan alkohol, serta permasalahan dalam rumah tangga. Kekerasan anak dapat mencakup: penyiksaan jasmani, penyiksaan emosi, pengabaian, dan pelecehan seksual. Permasalahan ini yang dirasa tepat untuk menjadi latar belakang konflik pada film fiksi horror yang akan dibuat dengan menggunakan tata cahaya yang akan mendukung unsur dramatis.

Film horor "Derana Dara" mengisahkan tentang sebuah keluarga baru yaitu Laura, Deni dan putri mereka yang bernama Dara. Keluarga ini semula sangat harmonis, namun berubah menjadi berantakan karena kelakuan bejat Deni, yang menyebabkan Dara trauma yang pada akhirnya menyebabkan Dara bunuh diri, lalu menghantui ibunya untuk balas dendam.

Tata cahaya high contrast yang akan digunakan didalam film "Derana Dara" Tata cahaya akan membangun mood dan suasana yang bersifat dingin, intim bernuansa misteri, serta mencekam. Perancangan tata cahaya sendiri merupakan faktor pendukung unsur dramatis secara visual, dengan tata cahaya high contrast yang di mendominasi detail seperti texture, bayangan, dan kedalaman ruang akan meningkatkan kesan menakutkan, dan mencekam. Elemen natural seperti cahaya kilatan petir akan mendukung suasana mencekam dan meneggangkan di dalam film "Derana Dara"
\end{abstract}

Kata Kunci: Film, Unsur Dramatis, Tata Cahaya High Contrast. 


\section{Pendahuluan}

Anak adalah sebuah anugerah yang dititipkan oleh tuhan kepada keluarga, sudah semestinya para orang tua menjaga buah hatinya, namun maraknya pemberitaan di media masa mengenai kekerasan terhadap anak sangat banyak. Sistem Informasi Online Perlindungan Perempuan dan Anak (Simfoni PPA) menerima lebih dari empat ribu laporan kekerasan terhadap anak sepanjang 1 Januari hingga 24 Juli 2020, bahkan kekerasan sering terjadi pada anak dibawah umur. 1.111 anak mengalami kekerasan fisik, 979 anak mengalami kekerasan psikis, 2.556 anak menderita kekerasan seksual, 68 anak menjadi korban eksploitasi, 73 anak menjadi korban perdagangan orang, dan 346 anak menjadi korban penelantaran, $\quad 58,80 \% \quad$ kasus kekerasan terhadap perempuan dan anak itu terjadi di dalam rumah tangga

(https://www.voaindonesia.com

diakses pada kamis 28 Desember 2020). Menurut Suharto (Hueraerah, 2012) dalam buku kekerasan terhadap anak bahwa faktor penyebab kekerasan terhadap anak adalah: kemiskinan keluarga, orang tua menganggur, keluarga tunggal atau broken home, keluarga belum matang secara psikologis. Kekerasan anak dapat mencakup: penyiksaan jasmani, penyiksaan emosi, pengabaian, dan pelecehan seksual. Permasalahan ini yang dirasa tepat untuk menjadi latar belakang konflik pada film fiksi horror yang akan dibuat dengan menggunakan tata cahaya yang akan mendukung unsur dramatis.

Film horror adalah sebuah genre yang memiliki dramatisasi yang meliputi konflik dari karakter utama, rasa ingin tahu, unsur kejutan dan suspense yang akan diciptakan didalam setiap scene. Film horror sering melibatkan tema-tema halusinasi karakter utama, kematian, hantu, supranatural, atau penyakit mental. Salah satu unsur penting dalam film horor adalah tata cahaya. Tata cahaya merupakan salah satu dari elemen mise en scene sebagai pendukung unsur dramatis dan sebagai pembangun mood. Tata cahaya dibagi dua yaitu low contrast dan high contrast. Low contrast adalah teknik tata cahaya yang menciptakan batas tipis antara 
highlight dan shadow membuat perbedaan sangat tipis ini yang biasa disebut high key teknik ini bisa digunakan dalam iklan komersil, video clip dan dalam beberapa film yang mendukung konsep ini. Sedangkan high contrast adalah teknik tata cahaya yang membuat batasan antara highlight dan shadow sehingga menciptakan bayangan yang lebih dominan dalam sebuah frame teknik ini sangat sering digunakan untuk membangun dan mendukung kesan dramatis, misteri, kejutan, mencekam, sedih, dan romantis dalam film sering menggunakan teknik high contrast ini biasanya bergenre drama, horror, noir, detektif, thriller dan romance. Penerapan teknik high contrast ini menjadi teknik yang untuk mendukung setiap unsur dramatis dalam film horror yang disesuaikan dengan mood dalam film "Derana Dara" dimana ada beberapa didalam scene yang butuh dukungn tata cahaya untuk mendukung unsur dramatis dari terror hantu yang membuat kehidupan karakter utama jadi tidak tenang. Ada juga scene yang membutuhkan unsur dramatis curiosity atau rasa ingin tahu dengan dukungan high contrast saat karakter mencari sesuatu di dalam kegelapan penonton akan di beritahu keberadaan hantu melalui kilatan petir. Ada juga teknik high contrast yang akan digunakan dalam scene ada perpaduan masa kini dan masa lalu dan akan ditunjukan dengan tata cahaya yang akan dibuat dengan lampu akan menyala untuk menujukan kejadian masa lalu dan mati saat karakter utama melewatinya dibuat dengan gaya tata cahaya pictorial light untuk mendukung unsur dramatis dan mood.

Film "Derana Dara” akan banyak menampilkan adegan pada waktu malam hari, dan penggunaan tata cahaya yang akan mendukung mood dan suasana setting gelap akan bersifat dingin, mencekam, dan bernuansa misteri. Himawan menjelaskan dalam buku memahami film, elemen natural seperti hujan dan kilatan petir dapat mendukung mood dan unsur dramatis. Perancangan tata cahaya sendiri merupakan faktor pendukung unsur dramatis secara visual, dengan high contrast yang di mendominasi gelap akan membangun seperti texture, bayangan, dan 
kedalaman ruang. Film "Derana Dara" pada setiap scene yang memiliki unsur dramatis yang akan didukung dengan teknik tata cahaya high contrast. Penggunaan tata cahaya high contrast dalam beberapa scene mampu mendukung kesan kejutan juga membangun unsur mencekam dan suspense, didalam film horror "Derana Dara" menjadi menarik jika unsur dramatis muncul didukung dengan tata cahaya. Pencahayaan yang akan digunakan untuk mendukung unsur dramatis adalah pencahayaan high contrast.

film "Derana Dara" tata cahaya dengan teknik high contrast yang akan menggunakan dua gaya yaitu natural light, artificial light dan pictorial light. Natural light pengguanaan tata cahaya ini akan diterapkan pada scene siang hari maupun malam hari dimana tata cahaya meneruskan dari sumber alami seperti matahari, bulan dan lampu yang ada didalam rumah Laura, artificial yang akan menggunakan teknik high contrast untuk medukung unsur dramatis ketika Laura merasa bahagia ketika keluarga Laura masih lengkap dengan
Dara dan Deni didalamnya, merasa sedih ketika kematian Dara, halusinasi ketika merias mayat. Pictorial light akan diciptakan sesuai kebutuhan artistik, naratif dan mood adegan di dalam film, pictorial light digunakan untuk mendukung unsur dramatis dimana Laura diteror oleh hantu dara melalui bayangan dan lampu yang berkedip secara tidak normal, perpindahan cahaya dari dunia nyata ke mimpi dan terror yang dirasakan oleh Laura sehingga melihat kesalahan di masa lalu melaui mimpi, pembalasan dendam dara terhadap Laura. Beberapa contoh scene atau adegan yang akan didukung dengan tata cahya high contrast natural light dan pictorial light akan menggunakan perbandingan rasio pada setiap scene yang berbeda, unsur dramatis yang dirasakan oleh Laura didalam film seperti sedih, senang, ketakutan, kejutan akan menggunakan perbandingan 1:8 dan perbandinagan 1:16 digunakan ketika kemunculan hantu Dara, halusinasi Laura, dan scene kematian dari Laura dan Dara. 


\section{Tinjauan Pustaka}

Film adalah rangkaian gambar yang bergerak yang membentuk suatu cerita dan biasa disebut movie. Film secara kolekif, sering disebut sinema. Film memiliki dua jenis yaitu film pendek adalah sebuah karya film cerita fiksi yang berdurasi kurang dari 60 menit. Film panjang adalah film cerita fiksi yang berdurasi lebih dari 60 menit, umunya berkisar antara 90100 menit. Film yang di bioskop adalah termasuk dalam kelompok ini (Javandalasta 2011:2) di dalam film memiliki beberapa jenis cerita yaitu drama komedi, drama laga, drama misteri, dan salah satunya adalah drama horror (Lutters 2004:37)..

Film horor adalah salah satu genre film yang sangat digemari dari dulu hingga sekarang dari beragam usia dari tua hingga muda. Film horror sangat banyak kita temui, mulai mengangkat cerita fiktif ataupun mengangkat legenda atau mitos dari beragam negara. Di Indonesia film horror sangat banyak macamnya mulai dari mitos, legenda, ataupun dari cerita fiktif pengarang. Dalam bukti Elizabeth Lutters yang berjudul Kunci Sukses Menulis Sekenario
(Lutters 2010:37) film horror adalah cerita tentang hal-hal yang berkaitan dengan roh halus atau makhluk yang menakutkan semacam setan.

Di dalam film horor memiliki tujuan utama memberikan efek rasa takut, kejutan, serta teror yang mendalam bagi penontonnya. Plot film horor sederhana yakni bagaimana usaha manusia untuk melawan kekuatan jahat dan biasanya berhubungan dengan dimensi spiritual dalam buku memahami film menjelaskan dalam film horor umumnya memiliki setting gelap dan dengan dukungan ilustrasi musik yang mencekam. (Pratista 2008:16)

Adegan bisa juga disebut scene yaitu segmen pendek dari keseluruhan cerita yang memperlihatkan satu aksi berkesinambungan yang diikat ruang, waktu, isi (cerita), tema, karakter, atau motif. Satu adegan terdiri dari beberapa shot yang saling berhubungan, dalam film terdiri dari tiga puluh sampai lima puluh adegan atau scene (Pratista 2008:29). Biran menjelaskan pada bukunya defenisi dari scene adalah peristiwa atau hal yang berlangsung di suatu tempat dan 
suatu waktu tertentu (Biran 2006:282).

Dramatisasi terhadap sesuatu adalah dengan membuat sesuatu itu berada pada situasi dramatis. Dalam skenario harus juga termuat unsur dramatis. Unsur dramatisdalam istilah lain juga disebut dramatugi, yakni unsur-unsur yang dibutuhkan untuk melahirkan gerak dramatis ada cerita atau pada pikiran penontonya (Lutters 2004:100). Ada beberapa unsur dramatisyang dijelaskan dalam buku Teknik Menulis Sekenario Film Cerita dan ciri khasnya (Biran 2006:106).

Mise-en-scene adalah segala hal yang terletak di depan kamera. Miseen-scene adalah unsur yang paling mudah kita kenali karena hampir semua yang berada dalam film yang kita lihat meliputi unsur ini, dan berasal dari bahasa prancis yang memiliki arti putting in the scene. Mise-en-scene secara harfiah berarti mementaskan sebuah adegan didukung sebuah setting, pencahayaan, make up, wardrobe, dan properti. Sutradara disetujui oleh divisi kreatif lainnya seperti divisi kamera, tata cahaya, artistik, make up,

dan wardrobe dalam perancangan mise-en-scene. Dalam buku Film $A$ Critical Introduction second edition menjelaskan bahwa dalam mise-enscene memiliki element meliputi setting, pemain, pencahayaan, dan komposisi kamera untuk mempengaruhi penonton untuk mendukung cerita, karakter, ruang dan waktu dalam cerita. (Pramaggiore \& wallis 2008:89). Di atas menjelaskan mise-en-scene adalah nyawa dari sebuah film karena tanpa adanya mise-en-scene sebuah film akan terasa flat atau tanpa emosi. Mise-en-scene adalah segala hal yang terletak di depan kamera yang akan diambil gambarnya selama proses produksi sebuah film. Hampir seluruh hal yang bisa dilihat pada gambar di dalam film termasuk ke dalam miseen-scne. Empat aspek utama di dalam mise-en-scene adalah setting/latar, kostum dan make up, tata cahaya, serta pergerakan pemain (Pratista, 2008: 1-2).

Empat faktor dari mise-en-scene di atas, mengandung unsur sebagai pendukung unsur dramatis, mood dan suasana antara lain yaitu setting/latar, dan tata cahaya 
Berdasarkan buku sebenarnya.Gambar yang bermakna "Cinematography Theory and adalah gambar yang setiap aspeknya Pratice" yang disusun oleh Blain memiliki nilai emosional, simbol, dan Brown adalah cinematography pemaknaan konotasi.Tidak ada aspek berasal dari kata Yunani, yaitu kinema, jadi cinematography bisa juga diartikan dengan "menulis dengan gambar bergerak". Membuat film tidak hanya merekam setiap adegan, melainkan bagaimana mengontrol dan mengatur setiap adegan yang diambil seperti jarak, ketinggian, sudut, lama pengambilan, dan lain-lain. Hal ini bertujuan untuk memperlihatkan atau menjelaskan objek tertentu secara mendetail. Blain Brown menjelaskan cinematography lebih dari sekedar aksi fotografi tetapi proses mengambil ide, kata-kata, tindakan, subteks emosional, nada, dan semua bentuk lain dari komunikasi nonverbal dan menjadikan dalam bentuk visual.( Brown 2012:2)

Rangkaian gambar ini akan membentuk sebuah cerita. Salah satu hal yang paling penting pada cerita film adalah unsurdramatisasiyaitu, kemampuan gambar untuk menyampaikan makna yang didalam gambar yang terekam tanpa rencana. Setiap elemen, setiap warna, setiap bayangan memiliki tujuan untuk menyampaikan cerita (Brown, 2012: 68).

Dari teori diatas menjelaskan bahwa tata cahaya bisa mendukung unsur aspek dramatis yaitu ketegangan dan emosi di dalam film. Unsur dramatis akan dibuat dengan teknik tata cahaya High contrast yang dibuat melalui kontras yang tinggi. Film horor "Derana Dara" pada area gelap akan menimbulkan ketegangan yang akan di rasakan penonton berharap-harap cemas akan apa yang akan muncul dari balik bayangan.

Cahaya adalah unsur media visual, karena dengan cahayalah informasi bisa dilihat. Cahaya pada mulanya hanya merupakan unsur teknis yang membuat benda bisa dilihat. Maka penyajian film juga, pada mulanya disebut painting with light namun dalam perkembangan bertutur tata cahaya memiliki banyak 
fungsi yaitu mampu menjadi informasi waktu, menunjang mood atau atmosphere, dan bisa menunjang dramatisadegan (Biran 2006:48). Tata cahaya di bagi menjadi dua yaitu natural light dan juga pictorial light.

a. Natural light

Pencahayaan yang berasal dari sumber cahaya alami seperti cahaya matahari, cahaya bulan, cahaya yang sduah ada di tempat seperti lilin atau lampu ruangan. (Luccitti 1995:138)

b. Artificial Light

Jhony Alton menjelaskan artificial light adalah cahaya buatan yang menyerupai sumber alaminya seperti: cahaya matahari, cahaya bulan, cahaya lampu, cahaya lilin, cahaya senter, cahaya petir dan lampu jalan. (Alton 1995:31)

c. Pictorial light

Pencahayaan yang bersifat artistik atau ciptaan. Dibentuk sesuai kebutuhan artistik, mood sebuah adegan atau scene. Jadi sumber cahaya (key light) dapat berubah-ubah sesuai kebutuhan artistik, mood, dari untuk alasan teknis. Dalam bukunya Brown menjelaskan tentang perbedaan periode naturalism (sesuai kenyataan, cahaya buatan pada umunya, cahaya flat). Appia menjelaskan membuat cahaya ekpresionis dengan pencahayaan tebal yang menyimpang dari cahaya ideal untuk membuat cahaya lebih pictorial (bergambar) dan untuk alasan teknis (Brown:2007:2).

High contrast terinspirasi dari pelukis Caravaggio dan Rembrandt yang mengembangkan lukisan tiga dimensi dengan gaya contrast dengan perbedan cahaya dan bayangan yang sangat kuat, lukisan mereka sering di terangi dengan cahaya yang terang degan latar background yang gelap, gaya lukisan ini sering disebut Chiaroscuro. Teknik high contrast biasa di gunakan di acara televisi seperti film detektif, psychodrama, misteri, horor, dan film noir.

High Contrast juga sering juga disebut low key adalah teknik pencahayaan yang menciptakan batasan yang tegas antara area gelap yang menghasilkan bayangan kuat. Dalam buku film and video lighting terms and concepts menjelaskan 
bahwa high contrast adalahjenis pencahayaan yang menekankan dominasi kegelapan dan bayangan. Holben menjelaskan dengan arah lampu dari samping side light dengan high contras akan menciptakan tampilan yang sangat dramatis (Holben 2012:125).

Teknik pencahayaan ini biasanya meningkatkan kontras dan memiliki persaingan antara terang dan gelap dalam komposisi selain itu untuk mengambil dan memandu perhatian penonton. Kontras yang tinggi diciptakan oleh sumber cahaya yang keras dan sebagian besar digunakan untuk mengungkapkan detail dalam objek seperti tekstur, bayangan dan bentuk untuk membangun kesan mencekam dan dramatis. Kontras tinggi dan bayangan yang kuat akan memberikan kegelapan, pencahayaan yang rendah sebagian besar digunakan untuk meningkatkan ketegangan di dalam film (Tavakoli 2015:39). Bayangan diciptakan dari cahaya yang terang semakin terang cahaya semakin gelap bayangan yang ditimbulkan. Dalam film horor bayangan sangat sering di gunakan untuk mendukung unsur dramatis karena dengan bayangan penonton akan cemas apa yang akan datang di balik gelapnya bayangan itu. Buku $A$ Shot In The Dark menjelaskan Dengan tata cahaya high contrast dengan efek silhouette akan meningkatkan unsur dramatis (Holben 2012:65).

Jackman juga menjelaskan bahwa semakin penonton tidak tau tentang informasi yang dirasakan oleh karakter akan meningkatkan ketegangan yang di harapkan penonton

Pembunuhnya menguntit pahlawan kita di gudang. Dimana dia? Sebagian besar gudang gelap, dengan area dengan cahaya yang sangat redup. Kolam kecil dan tebasan cahaya ada di sana-sini, dari pintu, dari jendela kecil. Hanya ada cukup cahaya bagi penonton untuk melihat sekilas pembunuh di belakang sang pahlawan. Tetapi ketika pahlawan berputar, tidak ada yang terlihat. Penambahan musik tajam dan bidikan yang dipilih dengan cermat dapat membangun ketegangan tingkat tinggi (Jackman 2010: 164)

Dengan bantuan tata cahaya dengan teknik high contrast dimana banyak area gelap daripada area terang informasi dalam sebuah film akan semakin terbatas dan membuat penonton merasa cemas tentang apa yang akan di hadapi oleh karakter 
utama. Buku Lighting for digital film and video menjelaskan tentang lighting effects memiliki dua jenis teknis untuk mendukung unsur dramatis yaitu efek cahaya kilat dan efek cahaya dari api (Jackman 2010:199). Dari dua efek di atas film "Derana Dara" akan menggunakan efek kilat untuk mendukung unsur dramatis dimana setiap kilatan akan terlihat sosok hantu meneror tokoh. Penerapan high contrast pada film "Derana Dara" adalah menggunakan pictorial lighting dengan efek petir, dimana dalam buku Memahami Film, bahwa cahaya dari sambaran petir sering digunakan untuk membangun nuansa mencekam dalam film (Pratista 2008:6)

\section{Metode}

Tata cahaya adalah salah satu unsur paling penting dalam sinematografi kenapa karena tanpa adanya cahaya kamera tidak dapat merekam objek, karena pada dasarnya gambar yang ada dalam kamera adalah hasil dari manipulasi cahaya. Tata cahaya dalam film secara umum dikelompokan menjadi empat unsur yaitu kualitas cahaya, arah cahaya, warna cahaya dan sumber cahaya empat unsur ini mempengaruhi tata cahaya untuk membutuk suasana, mood dan unsur dramatis. Konsep tata cahaya dalam penciptaan karya seni "Derana Dara" sebagai pendukung unsur dramatis akan di dukung dengan menggunakan tata cahaya high contrast untuk membangun suasana yang dirasakan pada setiap scene.

Mise en scene merupakan elemen utama untuk mendukung unsur dramatis, salah satunya dengan tata cahaya. Kontras cahaya akan digunakan sesuai dengan tujuan karya yaitu sebagai pendukung mood dan suasana di dalam film. Setiap scene memiliki tangga dramatis yang berbeda-beda, seperti scene memiliki unsur konflik, suspense (tegang), kejutan (surprise), dan curiosity (rasa ingin tau). Kontras tata cahaya akan diterapkan sesuai dengan apa yang diinginkan oleh sutradara maupun senimatografer atau DOP dalam memanfaatkan mise en scene yang ada sesuai kebutuhan naratif. Melalui proses pembacaan naskah dan mengamati dari cerita dari film "Derana Dara akan dilakukan pengumpulan adegan atau scene yang 
memiliki unsur dramatis yang akan didukung dengan tata cahaya high contrast, dengan menggunakan perbandingan 1:8 dan juga menggunakan perbandingan 1:16 dengan gaya natural light atau gaya pictorial light.

Film yang berdurasi 25 menit yang terdiri dari 30 scene di awali dari scene 1A flashcack dan untuk penggunaan high contrast dalam pendukung unsur dramatis lainya ada pada scene $2,3,5,8,9,10,14,16,17$ 17B, 20, 21, 22, 23, 24, 25, 28, 29, 30, 31. Setelah membaca naskah dan menganalisis ada pokok pembahasan dalam film "Derana Dara” yaitu

1. Konsep high contrast sebagai pendukung unsur dramatis film "Derana Dara"

2. Penggunaan lighting ratios $1: 8$ dan 1:16, gaya natural light dan pictorial light sebagai pendukung unsur dramatis senang, sedih, kejutan, takut, dan seram.

Penggunaan high contrast dalam film "Derana Dara" akan mengikuti penjelasan tentang Blain Brown tentang visual storytelling bahwa tata cahaya mempunyai peran penting dalam mendukung unsur dramatik, dalam beberapa adegan perancangan pencahayaan merupakan salah satu factor pendukung unsur dramatis.

Floorplan dibutuhkan untuk mengetahui rancangan awal tentang semua yang ada didalam frame seperti artistik, property, blocking pemain, pergerakan kamera dan juga penempatan lampu. Florplan dibuat bertujuan mengetahui segala rancangan dalam film Derana Dara.

- 1G. INT. KAMAR DARA NIGHT

CAST : DARA, DENI

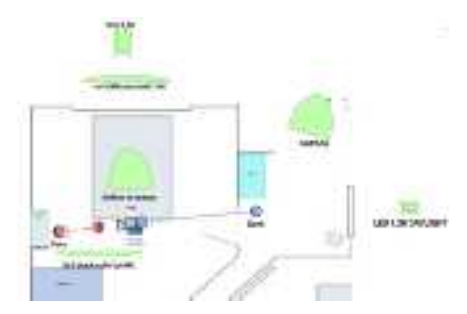

Gambar 4. 1 floorplan pada scene $1 \mathrm{G}$

Pada scene ini menggambarkan Dara yang bahagia di hari ulang tahunnya namun hancur saat ayah tirinya mau memperkosanya. Scene ini unsur dramatis yang akan digunakan pencahayaan high contrast untuk mendukung rasa takut Dara akan di perkosa oleh ayah tirinya penggunaan high contrast dalam 
scene ini akan menggunakan perbandingan rasio 1:16, dengan menggunakan lampu ARRI 2,5 KW dimana akan mempresentasikan dari cahaya yang bersumber dari cahaya matahari dan berfungsi sebagai key light dan lampu soft box yang akan di gantung di atap kamar berfungsi sebagai ambiance dan berfungsi seabagai fill light, frame 8x8 akan digunakan sebagai anti fill yang bearti mengurangi cahaya pendar dari lampu ARRI 2,5 KW yang menganai objek.

- 10. INT. SALON - NEXT DAY CAST : LAURA, 6-8 ORANG EKSTRAS, ARYA, DARA

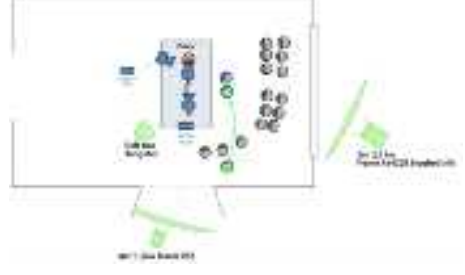

Gambar 4. 2 floorplan pada scene 10

Pada scene ini akan menggunakan pencahayaan high contrast dengan menggunakan perbandingan rasio 1:8 untuk mendukung kesedihan dan teror yang dirasakan oleh Laura. Karakteristik adegan pada scene ini dibangun saat Laura mencari lipstik di meja rias namun tiba-tiba lipstik tersebut menggelinding dibawah kaki Laura. Lampu yang akan digunakan sebagai key light adalah lampu ARRI 2,5 KW untuk mempresentasikan cahaya matahari yang masuk melalui jendela, sedangkan lampu ARRI 1,2 KW akan digunakan sebagai side light pada objek serta pemeran pendukung yang melayat, sedangkan lampu softbox akan digunakan sebagai top light dan berfungsi sebagai fill light dan mengisi ambiance didalam ruangan tersebut.

- 14. INT. KAMAR DARA NEXT DAY

CAST : LAURA

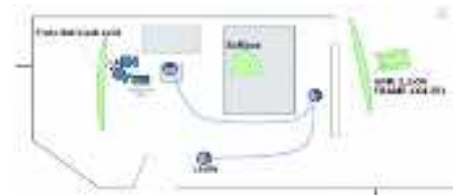

Gambar 4. 3 floorplan pada scene 14

Pada scene ini unsur dramatis yang akan dibangun dimulai saat Laura kembali lagi kekamar dara dan membuka jendela dan menemukan lipstik yang menggelinding dikakinya, ini awal mula Laura diganggu oleh hal hantu Dara melalui perantara lipstik merah tersebut. Pada scene ini high contrast akan di 
bangun melalui trobosan cahaya matahari yang masuk melalui jendela kamar Dara dengan perbandingan kontras cahaya 1:8 sebagai pendukung unsur dramatis .Saat Laura membersihkan lipstik yang tercoret dibibirnya lalu berubah menjadi lumuran darah, dengan kamar yang gelap cahaya hanya berasal dari tobosan matahari melalui jendela akan mendukung unsur dramatis dan membangun mood mencekam.

- 30. INT. KAMAR DARA NIGHT

\section{CAST: LAURA, DARA}

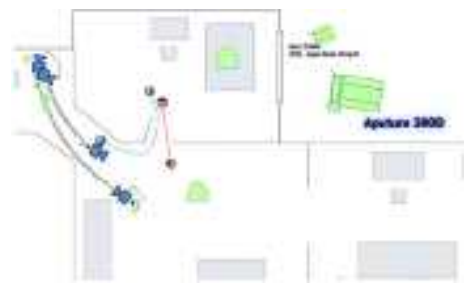

Gambar 4. 4 floorplan pada scene 30

Pada scene ini adalah ending dari film horor "Derana Dara" karena pembalasan dendam Dara untuk membunuh Laura dalam scene ini akan didukung dengan tata cahaya high contrast sebagai pendukung unsur dramatisakan menggunakan perbandingan 1:16 dimana menciptkan logika ruangan ketika keadaan mati lampu dan sumber utama berasal dari cahaya bulan dan kilatan petir yang akan meningkatakan keteggangan didalam film. Lampu yang akan digunakan yaitu ARRI 2,5 KW sebagai key light dengan tambahan filter lee aqua blue untuk menciptakan biru dari cahaya bulan. Lampu Aputure 300D akan menciptakan pictorial light dari efek petir dengan teknik strobe yang akan meningkatkan ketegangan didalam film.

\section{Pembahasan}

Proses pembuatan karya film drama horor "Derana Dara" telah melewati tiga tahapan yaitu tahap pra produksi, produksi dan pasca produksi tiga tahapan ini dikerjakan mengikuti standard operational procedure yang disingkat SOP. Film "Derana Dara" adalah karya tugas akhir dengan genre drama horror. Mengankat isu tentang kekerasan yang terjadi terhadap anak yang membuat depresi dan bisa mengakibatkan bunuh diri.

Unsur dramatis didalam film seperti kejutan, rasa ingin tau, ketegangan, sedih, takut, dan marah akan didukung denghan tata cahaya high 
contrast untuk membangun unsur dramatis didalam film "Derana Dara". Tujuannya agar tata cahaya pada film dapat membangun unsur dramatis dengan dukungan high contrast, terhadap penonton yang melihat karya film ini.

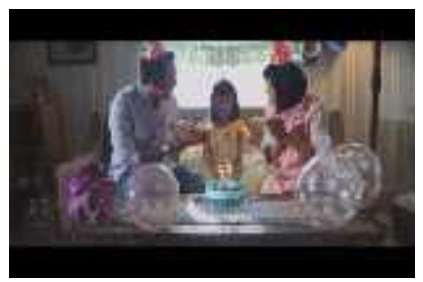

Gambar 5. 1 screenshot adegan flashback keluarga Laura yang bahagia dan harmonis

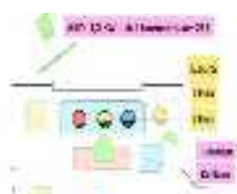

İ

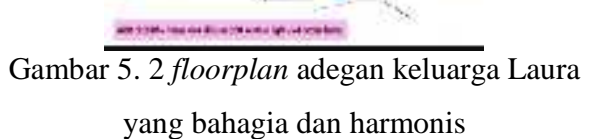

Unsur dramatis senang atau bahagia dalam scene ini melalui high contrast untuk mendukung suasana yang dirasakan oleh keluarga Laura saat merayakan ulang tahun Dara. Dalam scene ini menggunakan artificial light.

High contrast pada adegan ini dibangun dengan lighting ratio 1:8 untuk menggambarkan mood bahagia dan bantuan standing lamp yang berjenis lampu tungsten memberi nuansa hangat dan bahagia, selain itu untuk skin tone dari objek agar kulit karakter tidak terlihat pucat karena terkena lampu yang berwarna putih. Perbandingan lighting ratio 1:8 dengan selisih 3 stop antara key light $\mathrm{f} / 4$ dan fill light $\mathrm{f} / 2$ berhasil mendukung nuansa dramatis senang yang dirasakan oleh karakter pada scene ini.
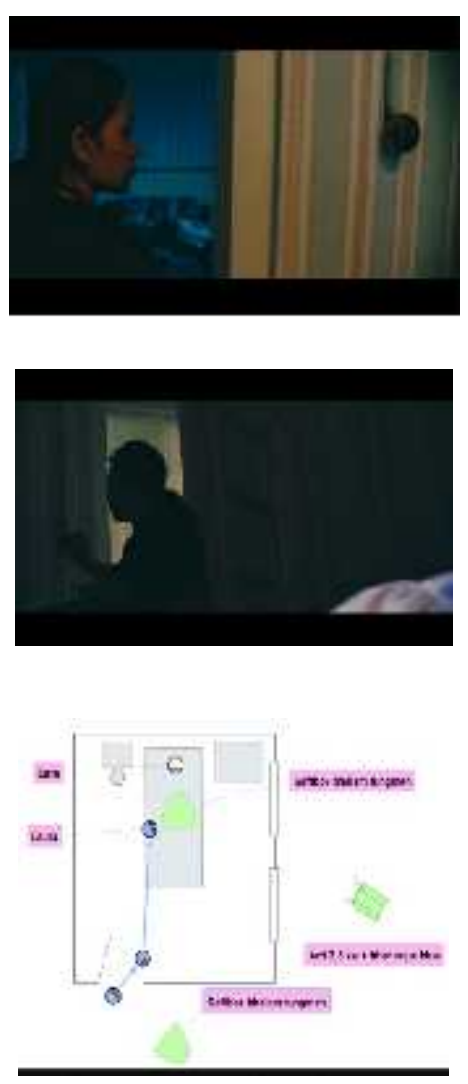

Gambar 5. 3 screenshoot, floorplan INT kamar Dara Bunuh diri

Scene ini menunjukan unsur dramatis curiosity atau rasa ingin tau Laura, ketika makanan di meja masih utuh dan hendak mengantar makan 
malam untuk Dara barulah Laura tau didalam kegelapan Dara sudah meninngal. Teknik tata cahaya disini adalah artificial light dimana tata cahaya dibuat seolah berasal dari sumber cahaya yang sudah ada. Teknik tata cahaya pada adegan ini mendukung rasa ingin tau Laura dan penonton apa yang terjadi dengan Dara didalam kegelapan, ketika lampu menyala barulah informasi bahwa Dara sudah bunuh diri terlhat.

Tata cahaya high contrast pada scene ini menggunakan lighting ratio 1:16 dengan perbandingan 4 stop ketka lampu kamar Dara mati, dan perbandingan lighting ratio 1:8 3 stop digunakan ketika lampu kamar Dara dihidupkan. High contrast akan mendukung unsur dramatis curiosity atau rasa ingin tau Laura tentang yang terjadi didalam kegelapan dan menambah unsur kejutan dan mencekam. HMI ARRI 2,5 KW akan mepresentasikan cahaya bulan yang menyinari kamar Dara, dengan menambahkan filter cosmetik aqua blue untuk menciptakan cahaya berwarna biru dan lampu softbox berjenis tungsten digunakan sebagai lampu rumah yang dihidupkan oleh Laura.
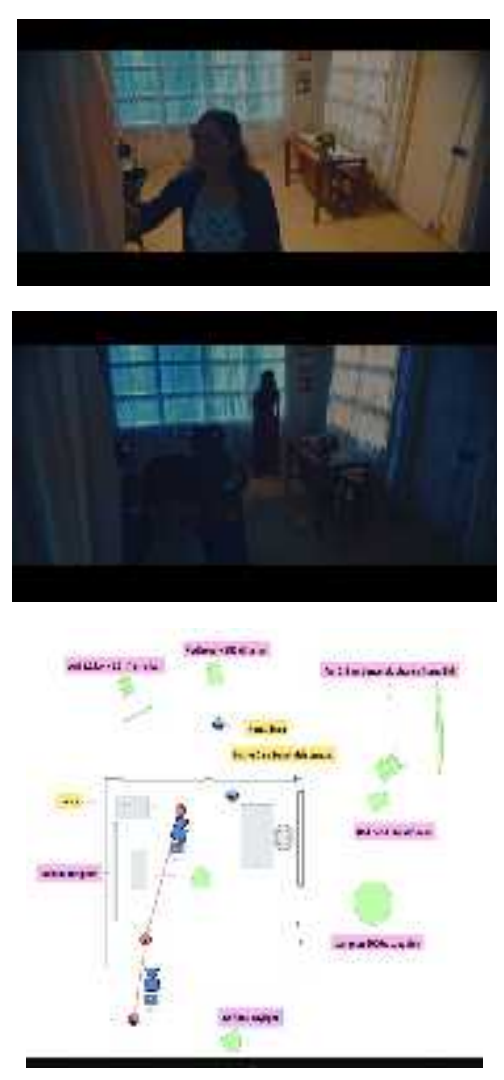

Gambar 5. 4 screenshoot dan floorplan penampakan hantu Dara.

Pada scene ini pertama kali hantu Dara muncul dihadapan Laura didalam kegelapan tetapi Laura tidak mengetahui siapa sosok didalam kegelapan itu. Pada scene ini tata cahaya high contrast mendukung unsur dramatis kejutan ketika tibatiba hantu Dara berada didalam rumah ketika Laura mematikan lampunya. 
Tata cahaya high contrast pada scene ini menggunkan perbandingan 1:8 ketika lampu menyala dan ketika lampu mati menggunakan 1:16 dimana high contrast digunkan menciptakan mood menakutkan dan kelam. Tata cahaya pada scene ini menggunakan teknik pictorial light dimana menciptakan cahaya yang berkedip tidak normal menunjukan keberadaan hantu Laura. Lampu pada scene ini menggunakan kombinasi dari dua jenis lampu yaitu jenis lampu daylight yaitu lampu HMI ARRI 2,5 KW, HMI ARRI 1,2KW dan berjenis tungsten yaitu red head dan lampion 2000w.
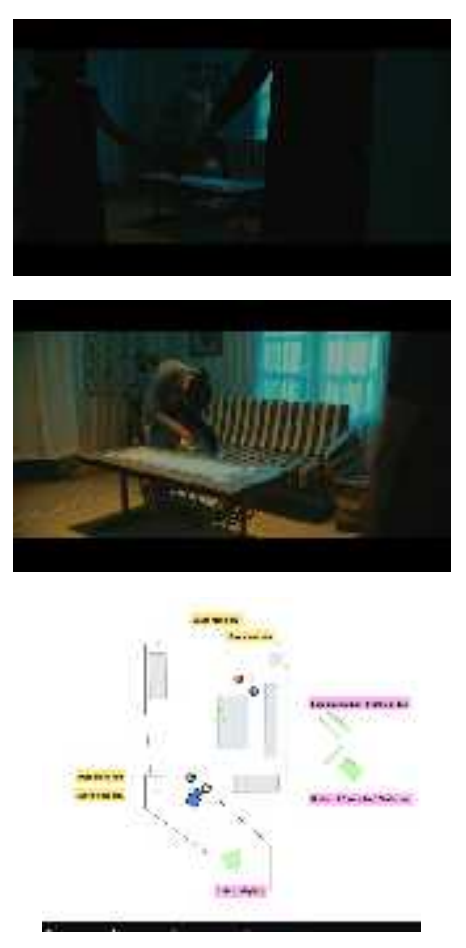

Gambar 5. 5 screenshoot dan floorplan Laura melihat kejadian dimasa lalu sedang menyiksa Dara

Unsur dramatis pada scene ini didukung dengan tata cahaya high contrast untuk menunjukan kesedihan yang dirasakan Dara pada masa hidupnya. Ketika lampu menyala, terlihat Laura masa lalu sedang menyiksa Dara, Laura yang sedang melihat kejadian itu merasa tidak percaya akan yang dilakukan pada masa lalu. Tata cahaya high contrast pada scene ini menggunakan teknik pictorial light dimana lampu blonde akan hidup perlahan untuk memperlihatkan adegan Laura menyiksa Dara, blonde akan dihidupkan dengan menggunakan dimmer agar lampu bisa hidup dengan perlahan. HMI ARRI 2,5 KW dengan tambahan filter cosmetic aqua blue mempresentasikan cahaya bulan dan membangun mood menakutkan di dalam scene ini. Perhitungan ratio 1:16 key light $\mathrm{f} / 5.6$ dan fill light $\mathrm{f} / 1.4$ ketika lampu mati, berubah perhitungan menjadi 1:4 key light f/5.6 dan fill light f/2 ketika lampu menyala. Penggunaan kaca untuk memnatulkan cahaya yang tidak 
dapat dijangkau oleh lampu dengan tambahan filter brush slik agar cahaya tetap keras namun bayangan yang dihasilkan lembut.
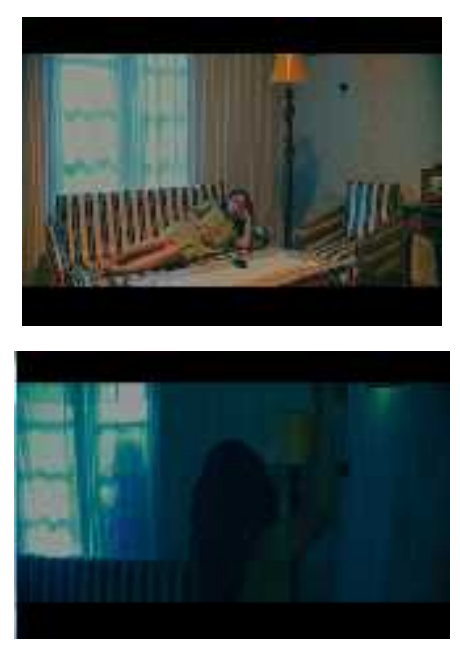

Gambar 5. 6 screenshoot Dara memperlihatkan diri ke Laura

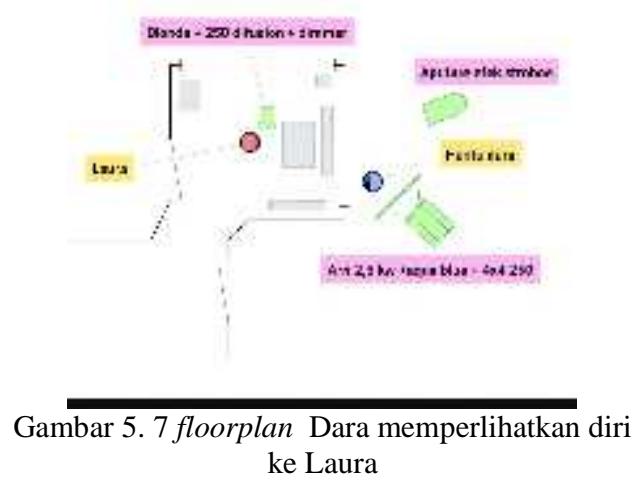

Scene ini adalah puncak dari film "Derana Dara" pada scene ini hantu Dara menunjukan kepada Laura rasa ingin balas dendam. Tata cahaya yang digunakan pada scene ini menggunakan teknik high contrast untuk mendukung unsur dramatis, mebangun mood mencekam dan menegangkan, dengan teknik pictorial light dimana penggunaan lampu Aputure dengan mengunakan efek stroboe untuk mempresentasikan cahaya petir untuk menambah unsur dramatis pada scene ini. Dengan menggunakan perbandingan ratio 1:16 ketika mati lampu akan mendukung keteggangan dengan perbedaan empat stop antara gelap dan terang, memiliki sisi gelap lebih dominan. Lampu HMI ARRI 2,5 KW mempresentasikan cahaya bulan dengan bantuan sound effect suara hujan. Dengan perbandingan key light $\mathrm{f} / 4$ dan fill light $\mathrm{f} / 1$ akan mendukung unsur dramatis yang dirasakan oleh Laura dan juga penonton yang melihatnya.

\section{PENUTUP}

Pada dasarnya tata cahaya adalah unsur paling penting didalam pembuatan film, karena dengan tidak adanya tata cahaya, kamera tidak dapat merekam objek dengan maksimal. Dalam divisi tata cahaya kerjasama sangat dibutuhkan, karena dengan kerjasama yang baik perkerjaan tata cahaya akan menjadi lebih mudah. Seorang penata cahaya 
harus memiliki rasa maupun yang di rancang pada tahap pra kepekaan terhadap sekitar, produksi.

dikarenakan semua elemen yang ada dapat mempengaruhi konsep tata

Selain paham tentang teknis dan cahaya yang sudah dibuat, seorang penata cahaya harus memiliki banyak refrensi agar mudah mempresentasikan tata cahaya seperti apa yang akan dibuat kepada sinematografer dan sutradara, Kumpulan refrensi tersebut dapat dibuat acuan konsep pada setiap film yang akan dibuat

Film pendek "Derana Dara" tata cahaya untuk mendukung unsur dramatis, ingin menyampaikan bahwa dengan dukungan tata cahaya yang kontras dapat mendukung suasan atau mood yang ingin disampaikan oleh sutradara didalam film. Unsur dramatis sedih, takut, ketegganan, rasa ingin tau, kejutan yang dirasakan karakter ataupun penonton dapat berhasil karena didukung dengan tata cahaya high contrast. Konsep tata cahaya high contrast telah terwujud dalam film "Derana Dara" sesuai kebutuhan dan pencapaian yang diinginkan dengan menaati konsep dan standart oprational procedure cara penggunaan alat seorang penata cahaya harus faham tentang konsep dan elemen mise en scene, supaya penata cahaya tidak hanya dianggap sebagai tukang lampu, karena pada dasarnya seorang penata cahaya juga harus ikut andil tentang konsep dan mood yang akan dibangun daalam sebuah film yang akan dikerjakan. Saran yang akan diberikan adalah selalu memperhatikan keselamatan, pada dasarnya divisi tata cahaya adalah divisi yang bahaya jika tidak dilakukan dengan benar, karena berkaitan dengan listrik, barangbarang yang terbuat dari besi. Banyak kejadian tim penata cahaya terjatuh bahkan sampai meninggal karena tidak memperhatikan saftty, ada juga lampu yang jatuh saat digantung ketika memasang lampu dengan tidak benar dan hati hati.

\section{DAFTAR RUJUKAN}

\section{Buku:}

B Biran. (2010). Teknik Menulis Skenario Film Cerita. Jakarta: Fakultas Film dan Televisi IKJ. 
Blain, Brwon. (2012).

Cinematography Theory and Pratice. China: Focal Press Books

Holben, Joy. (2012) A Shot In The Dark. Boston: Course Tecnology, A Part Of Cengage Learning.

Huraerah, Abu. (2012) Kekerasan Terhadap Anak. Bandung: Nuansa Cendika

Jackman, Jhon. (2010) Lighting For Digital Video and Television Thrid Edition. USA: Focal Press Is An Imprint Of Elsevier.

Javandalasta, Panca. (2011). Lima Hari Mahir Bikin Film. Surabaya: Mumtaz Media.

Landau, David. (2004). Lighting For Cinematography A Partical Guide

To The Art And Craft Of Lighting For The Movung Image. New York: Bloomsbury

Lutters, Elizabeth. (2010). Kunci

Sukses Menulis Skenario. Jakarta: PT Grasindo

Pratista Himawan. (2008).

Memahami Film. Yogyakarta:

Homerian Pustaka.

Pramaggiore,Maria. Wallis, Tom. (2008). Film A Critical Introduction second edition. London: Laurence King Publishing Ltd.

Wheeler, Paul. (2001) Digital Cinematography. Woburn: Focal Press

\section{Sumber Online}

Tavakoli, Yousef. (2015). Analyzing The MiseEen Scene An Approach To Improve Achtectural Lighting Design Inspired By Visual. 